\title{
Knowledge of Coronary Heart Disease Risk Factors among a Community Sample in Oman Pillot study
}

*Ali A. Ammouri, ${ }^{1}$ Ayman Tailakh, ${ }^{2}$ Chandrani Isac, ${ }^{3}$ Joy K. Kamanyire, ${ }^{3}$ Joshua Muliira, ${ }^{3}$ Shreedevi Balachandran ${ }^{3}$

$$
\text { معرفة عوامل الخطر لأمراض القلب التاجية لدى عينة من البحتمع الملي في عمان }
$$$$
\text { علي أحمد عموري، أيمن طيلخ، شندراني اسحق، جوي كاباسيندي، جوشوا مولييرا، شريدييفي بالاشاندران }
$$

ABSTRAC T: Objectives: The aim of this study was to assess the knowledge of Omani adults regarding conventional coronary heart disease (CHD) risk factors and to identify demographic variables associated with these knowledge levels. Methods: This descriptive cross-sectional pilot study was carried out among a convenience sample of 130 adults attending a health awareness fair held in a local shopping mall in Muscat, Oman, in November 2012. A modified version of the Heart Disease Facts Questionnaire in both English and Arabic was used to assess knowledge of CHD risk factors. Scores were calculated by summing the correct answers for each item (range: 0-21). Inadequate knowledge was indicated by a mean score of $<70 \%$. Descriptive and multivariate logistic regression analyses were performed to establish the participants' knowledge levels and identify associated demographic variables. Results: A total of 114 subjects participated in the study (response rate: $87.7 \%$ ). Of these, 69 participants $(60.5 \%)$ had inadequate mean CHD knowledge scores. Knowledge of CHD risk factors was significantly associated with body mass index (odds ratio $[\mathrm{OR}]=0.739 ; P=0.023)$, marital status $(\mathrm{OR}=0.057 ; P=0.036)$ and education level $(\mathrm{OR}=9.243$; $P=0.006)$. Conclusion: Low knowledge levels of CHD risk factors were observed among the studied community sample in Oman; this is likely to limit the participants' ability to engage in preventative practices. These findings support the need for education programmes to enhance awareness of risk factors and prevention of CHD in Oman.

Keywords: Coronary Heart Disease; Knowledge; Risk Factors; Prevention; Oman.

الملخص: أهداف: هدفت هذه الدراسة لتقييم هعرفة البالغين العمانيين بعوامل الخطر لأمراض القلب التاجية التقليدية وتحديد المتفيرات

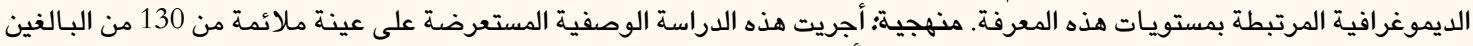

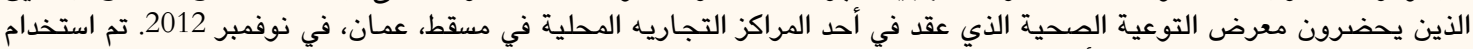

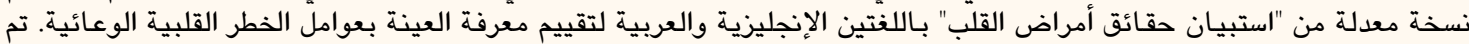

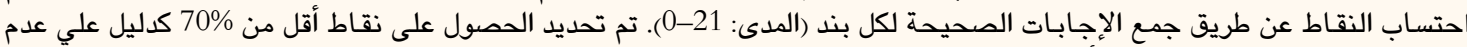

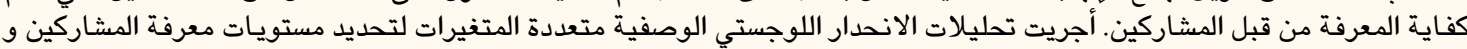

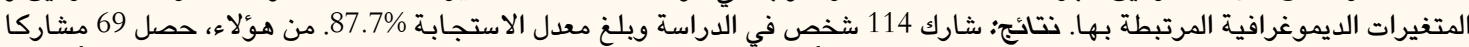

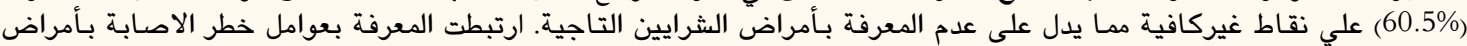

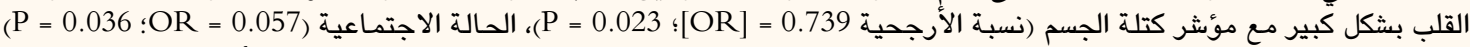

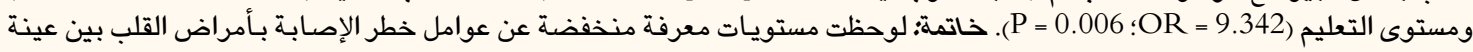

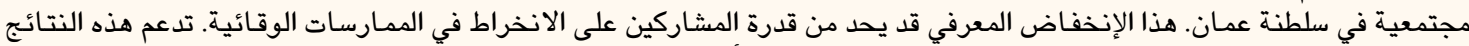

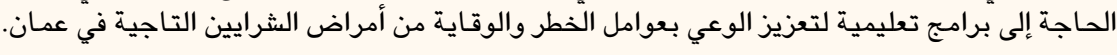

$$
\text { كلمات مفتاحية: مرض القلب التاجي؛ معرفة؛ عوامل الخطر؛ الوقاية؛ عمان. }
$$

\section{AdvanCES IN KNOWLEDGE}

This is the first study in Oman to highlight deficits in knowledge of coronary heart disease (CHD) risk factors among a community sample of Omani adults.

Several factors-including a high body mass index, low education levels and being married-were associated with low levels of CHD risk factor knowledge among the sample.

\section{Application to Patient Care}

The findings of this study contribute to existing knowledge regarding CHD in Oman and should be considered when planning and implementing targeted CHD health education and other preventative measures. Programmes to address the increasing burden of CHD in Oman should take into account the low levels of knowledge of CHD risk factors observed among the Omani community.

The results of this study highlight certain psycho-cognitive factors that require further exploration by healthcare services and researchers to enhance CHD risk factor knowledge and preventative lifestyle behaviours in Oman. 
$\mathrm{C}$ ORONARY HEART DISEASE (CHD) IS AN increasing worldwide health burden. According to the World Health Organization (WHO), there were 7.4 million deaths due to ischaemic heart disease in 2012, with high-income countries and upper-middle-income countries accounting for 158 and 107 deaths per million, respectively. ${ }^{1,2}$ While the prevalence of $\mathrm{CHD}$ has stabilised in developed countries, the condition has recently begun to impact developing countries due to increasing life expectancy, urbanisation and lifestyle changes; certain Middle Eastern countries (e.g. Bahrain, Kuwait, Oman, Qatar and the United Arab Emirates) are examples of areas experiencing this epidemiological transition. ${ }^{3}$ Modifiable risk factors such as hypertension, diabetes mellitus, hyperlipidaemia, a sedentary lifestyle, obesity and smoking are considered to be the main precursors of CHD. ${ }^{4}$

The increasing trend of CHD and its related risk factors has highlighted the need to strengthen national surveillance schemes and efforts to reduce CHD-related morbidity and mortality. Many countries have implemented a primary prevention approach; however, a key aspect affecting the success of this method is the knowledge of the individuals at risk regarding a specific health problem. ${ }^{5}$ Greater knowledge of CHD risk factors helps individuals to correctly assess their personal risk, motivates them to increase prevention-seeking behaviours and has been associated with increased action to lower risks. ${ }^{6-8}$ Estimating knowledge of traditional CHD risk factors among a population is therefore crucial in the prevention and treatment of this condition and continues to serve as the baseline for most screening programmes. ${ }^{9}$ Inherent psycho-cognitive factors such as the perceived risk of a disease or the importance of behavioural change as well as barriers to the adoption of preventative behaviours or CHD screening may contribute to lack of knowledge. , $7,10^{-}$

The population of Oman is currently approximately four million and life expectancy has recently increased (76.2 years in 2012 versus 73.3 years in 2010). ${ }^{11,12}$ Lifestyle changes, including an increase in sedentary lifestyles and a greater caloric intake, have contributed to a rapid rise in the incidence of $\mathrm{CHD}$; diseases of the circulatory system accounted for $32.5 \%$ of hospital deaths in Oman in 2012 versus 29.4\% of hospital deaths in $2010 .^{12}$ The prevalence of diabetes, hypertension and high serum cholesterol levels among Omani adults was $12.3 \%, 40.3 \%$ and $33.6 \%$, respectively, in 2008. ${ }^{13}$ Other surveys conducted in Oman have estimated the prevalence rates of overweight individuals, obesity and smoking in adults to be $67.4 \%, 30.9 \%$ and $13.5 \%$, respectively. ${ }^{14}$ Despite this threat, awareness and understanding of CHD are low in Oman and there is a significant lack of surveillance data for populations in the Middle Eastern region. ${ }^{15-17}$ Recent studies in this region have focused on screening for obesity, dietary patterns and diabetes mellitus. ${ }^{18-20}$ There is therefore an urgent need to understand baseline knowledge levels of CHD among the Omani population before designing appropriate and effective interventions to promote awareness. This study aimed to assess the knowledge of Omani adults regarding conventional CHD risk factors and to identify demographic variables associated with these knowledge levels.

\section{Methods}

This descriptive cross-sectional pilot study was carried out on a convenience sample of 130 Omani adults attending a health awareness fair held at a large shopping mall in Muscat, Oman, in November 2012. The fair was organised by faculty members of the College of Nursing at Sultan Qaboos University (SQU), Muscat, and provided community awareness activities and services with the goal of increasing public awareness about CHD. Omani adults $\geq 18$ years old who were not disabled or suffering from any medical conditions that prevented them from answering questions and who were not working in the healthcare profession were included in the study. Cohen's table was used to estimate a sample size allowing for the detection of a medium effect with a power of 0.80 and alpha of 0.05 with a regression analysis for seven variables. ${ }^{21}$ A sample of 107 participants was thus deemed adequate to ensure a description of variables in a single group and allow the researchers to control for type II errors. The effect size was estimated to be medium to account for the possibility that some participants had previously acquired CHD knowledge while seeking healthcare or from other sources.

In order to assess self-reported knowledge of $\mathrm{CHD}$ risk factors, participants were invited to complete the modified version of the Heart Disease Facts Questionnaire (HDFQ). ${ }^{22,23}$ The HDFQ was originally designed by Wagner et al. to measure CHD knowledge among diabetic patients utilising 25 true/ false questionnaire items and has demonstrated good psychometric properties, test-retest reliability $(r=0.89)$, internal consistency (Kuder-Richardson $r=0.77$ ) and excellent discriminant validity. ${ }^{22}$ The modified HDFQ contains 21 items measuring knowledge of CHD risk factors and methods of decreasing CHD risk. ${ }^{23}$ Each item on the modified HDFQ scale has three available responses: true, false or unknown. Scores were 
Table 1: Demographic characteristics and knowledge of coronary heart disease risk factors* among a community sample of Omani adults $(\mathrm{N}=114)$

\begin{tabular}{|c|c|}
\hline Characteristic & n (\%) \\
\hline Mean age in years (IQR) & $37.36(13.50)$ \\
\hline \multicolumn{2}{|l|}{$\mathrm{BMI}{ }^{+}$in $\mathrm{kg} / \mathrm{m}^{2}$} \\
\hline$<18.5$ & $2(2.0)$ \\
\hline $18.5-24.9$ & $27(27.3)$ \\
\hline $25.0-29.9$ & $42(42.4)$ \\
\hline$\geq 30.0$ & $28(28.3)$ \\
\hline Mean \pm SD & $27.47 \pm 4.12$ \\
\hline \multicolumn{2}{|l|}{ Gender } \\
\hline Male & $72(63.2)$ \\
\hline Female & $42(36.8)$ \\
\hline \multicolumn{2}{|l|}{ Marital status } \\
\hline Single & $32(28.1)$ \\
\hline Married & $82(71.9)$ \\
\hline \multicolumn{2}{|l|}{ Education level } \\
\hline Primary school & $10(8.8)$ \\
\hline High school & $36(31.6)$ \\
\hline Diploma & $26(22.8)$ \\
\hline Baccalaureate degree & $30(26.3)$ \\
\hline Graduate degree & $12(10.5)$ \\
\hline \multicolumn{2}{|l|}{ Employment status } \\
\hline Unemployed & $27(23.7)$ \\
\hline Employed & $87(76.3)$ \\
\hline \multicolumn{2}{|l|}{ Monthly income in $\mathrm{USD}^{+}$} \\
\hline$<\$ 1,300$ & $46(46.5)$ \\
\hline$>\$ 1,300$ & $53(53.5)$ \\
\hline \multicolumn{2}{|l|}{ CHD knowledge score } \\
\hline$<69.9 \%$ & $69(60.5)$ \\
\hline$\geq 70.0 \%$ & $45(39.5)$ \\
\hline Mean \pm SD & $13.52 \pm 4.59$ \\
\hline
\end{tabular}

calculated by summing the correct answers (range: $0-21)$. Statements with scores of $<70 \%$ and $\geq 70 \%$ were deemed to indicate low and adequate knowledge, respectively.22 The modified HDFQ instrument has also shown high internal consistency, with a Cronbach's alpha of $0.84 . .^{23}$ In this study, the Cronbach's alpha coefficient was 0.86 . The questionnaire was administered in both Arabic and English. The Arabic version was independently translated from the English instrument by three different postgraduate nurses who were proficient in both languages. They discussed and agreed on one version which was then back-translated by a bilingual expert. Both the translated and backtranslated forms were validated by two bilingual doctorate nurses specialising in cardiovascular care.

The demographic characteristics of the participants were recorded, including age, gender, marital and employment status, level of education and annual income. Body mass index (BMI) was calculated by dividing the participants' weight by their height. Weight was measured to the nearest $0.1 \mathrm{~kg}$ with portable digital scales and height was measured to the nearest $0.1 \mathrm{~cm}$ with a portable stadiometer. During these measurements, participants were requested to take off their shoes and any heavy clothing and to stand upright. Participants were then categorised according to their BMI as underweight $\left(<18.5 \mathrm{~kg} / \mathrm{m}^{2}\right)$, normal $\left(18.5-24.9 \mathrm{~kg} / \mathrm{m}^{2}\right)$, overweight $\left(25.0-29.9 \mathrm{~kg} / \mathrm{m}^{2}\right)$ or obese ( $\left.\geq 30.0 \mathrm{~kg} / \mathrm{m}^{2}\right)$, according to WHO standards. ${ }^{24}$

Data were entered into the Statistical Package for the Social Sciences (SPSS), Version 19, (IBM Corp., Chicago, Illinois, USA). Descriptive analyses were conducted and results presented as means \pm standard deviation and percentages. A multivariate logistic regression analysis was used to determine the associations between predictive variables (age, gender, BMI, education level, marital status, monthly income and employment) and the dichotomous dependent variable (knowledge of $\mathrm{CHD}$ ). These results were presented as odds ratios (ORs) and 95\% confidence intervals. A $P$ value of $<0.050$ was considered statistically significant.

This study received ethical approval from the Research \& Ethics Committee of the SQU College of Nursing (\#CRC/2012/20.9.2012). Individuals who expressed an interest in participating in the study were provided with detailed information about the study's purpose and procedures. Participants were assured that no information pertaining to their identity would be collected. Written consent was obtained from each of the subjects before their participation in the study.

\section{Results}

A total of 114 subjects participated in the study (response rate: $87.7 \%$ ). The demographic characteristics of the participants are presented in Table 1. Participants ranged in age from $18-80$ years old. The majority of the participants were male (63.2\%). The mean BMI was $27.47 \pm 4.12 \mathrm{~kg} / \mathrm{m}^{2}$ and the majority of the participants were categorised as overweight 
Table 2: Levels of accurate* knowledge of coronary heart disease risk factors ${ }^{\dagger}$ among a community sample of Omani adults $(\mathrm{N}=114)$

\begin{tabular}{|c|c|}
\hline Questionnaire item & n (\%) \\
\hline A person always knows when they have $\mathrm{CHD}$ & $39(34.2)$ \\
\hline $\begin{array}{l}\text { If you have a family history of } \mathrm{CHD} \text {, you are } \\
\text { at risk of developing heart disease }\end{array}$ & $68(59.7)$ \\
\hline $\begin{array}{l}\text { The older a person is, the greater their risk of } \\
\text { developing CHD }\end{array}$ & $81(71.1)$ \\
\hline Smoking is a risk factor for $\mathrm{CHD}$ & $112(98.3)$ \\
\hline $\begin{array}{l}\text { A person who stops smoking will lower their } \\
\text { risk of developing CHD }\end{array}$ & $100(87.7)$ \\
\hline $\begin{array}{l}\text { High blood pressure is a risk factor for } \\
\text { developing CHD }\end{array}$ & $100(87.7)$ \\
\hline $\begin{array}{l}\text { Keeping blood pressure under control will } \\
\text { reduce a person's risk for developing CHD }\end{array}$ & $101(88.6)$ \\
\hline $\begin{array}{l}\text { High cholesterol is a risk factor for } \\
\text { developing CHD }\end{array}$ & $97(85.1)$ \\
\hline $\begin{array}{l}\text { If your 'good' cholesterol (HDL) is high, you } \\
\text { are at risk for heart disease }\end{array}$ & $39(34.2)$ \\
\hline $\begin{array}{l}\text { If your 'bad' cholesterol (LDL) is high, you } \\
\text { are at risk for heart disease }\end{array}$ & $59(51.8)$ \\
\hline $\begin{array}{l}\text { Eating fatty foods does not affect blood } \\
\text { cholesterol levels }\end{array}$ & $86(75.4)$ \\
\hline $\begin{array}{l}\text { Being overweight increases a person's risk } \\
\text { of CHD }\end{array}$ & $100(87.7)$ \\
\hline $\begin{array}{l}\text { Regular physical activity will lower the risk of } \\
\text { developing heart disease }\end{array}$ & $104(91.2)$ \\
\hline $\begin{array}{l}\text { Only exercising at a gym or in an exercise } \\
\text { class lowers the risk of developing heart } \\
\text { disease }\end{array}$ & $46(40.4)$ \\
\hline $\begin{array}{l}\text { Walking and gardening are considered } \\
\text { exercise that will help lower the risk of } \\
\text { developing heart disease }\end{array}$ & 94. (82.5) \\
\hline Diabetes is a risk factor for developing $\mathrm{CHD}$ & $72(63.2)$ \\
\hline High blood sugar makes the heart work harder & $66(57.9)$ \\
\hline $\begin{array}{l}\text { A person who has diabetes can reduce their } \\
\text { risk of developing CHD if they keep their } \\
\text { blood sugar levels under control }\end{array}$ & $77(67.5)$ \\
\hline $\begin{array}{l}\text { Abdominal obesity is a risk factor for } \\
\text { developing CHD }\end{array}$ & $61(53.5)$ \\
\hline $\begin{array}{l}\text { Stress may cause an increase in blood sugar, } \\
\text { blood pressure and cholesterol levels }\end{array}$ & $72(63.2)$ \\
\hline $\begin{array}{l}\text { Slow deep breaths, counting to } 10 \text { before } \\
\text { speaking and going for a walk are examples } \\
\text { of stress inhibitors }\end{array}$ & $73(64.0)$ \\
\hline zeart disea & \\
\hline
\end{tabular}

(42.4\%). In terms of education level, a large proportion of the participants possessed a diploma qualification or higher (59.6\%). A total of 69 participants (60.5\%) had CHD knowledge scores $<70 \%$, indicating a low level of knowledge. The mean CHD knowledge score was $13.52 \pm 4.59$ and the mean percentage of correct answers was $64.4 \%$.

Participants showed adequate knowledge of certain CHD risk factors, such as smoking $(\mathrm{n}=112$; $98.3 \%)$, high blood pressure ( $\mathrm{n}=100 ; 87.7 \%)$, being overweight ( $\mathrm{n}=100 ; 87.7 \%)$, high cholesterol levels $(\mathrm{n}=97 ; 85.1 \%)$ and age $(\mathrm{n}=81 ; 71.1 \%)$. The majority also demonstrated adequate knowledge regarding several CHD prevention measures, such as regular physical activity ( $\mathrm{n}=104 ; 91.2 \%$ ), blood pressure control $(\mathrm{n}=101 ; 88.6 \%)$ and smoking cessation $(\mathrm{n}=100 ; 87.7 \%)$. However, fewer participants demonstrated correct knowledge of other CHD risk factors, including diabetes ( $\mathrm{n}=72,63.2 \%)$, stress ( $\mathrm{n}=72 ; 63.2 \%)$, a family history of CHD ( $\mathrm{n}=68 ; 59.7 \%)$ and abdominal obesity $(\mathrm{n}=61 ; 53.5 \%)$. Fewer subjects were aware of high-density lipoproteins (HDL) and low-density lipoproteins (LDL) as risk factors ( $\mathrm{n}=39 ; 34.2 \%$ and $\mathrm{n}=59 ; 51.8 \%$, respectively). Only 39 participants correctly responded that individuals with CHD might not be aware of their condition (34.2\%). While two of the three questionnaire items relating to physical activity were identified correctly by over $80 \%$ of the cohort, $59.6 \%$ of the participants believed that exercising in a gym or class was the only for of physical actively which lowers the risk of CHD [Table 2].

A multiple logistic regression analysis was performed to predict CHD knowledge. The model fit the data well (Chi-squared value $=23.42, P<0.001$; goodness of fit $=6.38, P=0.609$ ). The only modifiable factor that was significantly associated with knowledge of CHD risk factors was a BMI of $\geq 25 \mathrm{~kg} / \mathrm{m}^{2}$ (OR $=0.739 ; P=0.023)$, indicating that participants with a BMI of $\geq 25 \mathrm{~kg} / \mathrm{m}^{2}$ had $73.9 \%$ less knowledge than participants with a BMI of $<25 \mathrm{~kg} / \mathrm{m}^{2}$. Demographic variables significantly associated with knowledge of CHD risk factors included being married $(\mathrm{OR}=0.057 ; P=0.036)$ and having a diploma, baccalaureate or graduate educational qualification $(\mathrm{OR}=9.243 ; P=0.006)$. This indicates that married participants had $5.7 \%$ less knowledge than unmarried participants and participants with a diploma or higher education level had knowledge scores which were 9.2\% higher than those with less education [Table 3].

\section{Discussion}

The purpose of this study was to assess knowledge of CHD risk factors and identify demographic variables associated with knowledge levels among a community sample of adult Omanis. The mean score obtained 
Table 3: Multivariate logistic regression analysis" of associations between predictive variables and knowledge of coronary heart disease risk factors ${ }^{\dagger}$ among a community sample of Omani adults $(\mathrm{N}=114)$

$\begin{array}{lcccc}\text { Variable } & \begin{array}{c}\text { Beta } \\ \text { estimate }\end{array} & \begin{array}{c}\boldsymbol{P} \\ \text { value }\end{array} & \text { OR } & \mathbf{9 5 \% ~ C I} \\ \text { Intercept } & 9.460 & 0.010 & - & - \\ \text { Age }^{\ddagger} & 0.041 & 0.304 & 1.041 & 0.964-1.130 \\ \text { BMI of } \geq 25 \mathrm{~kg} / \mathrm{m}^{2} & -0.302 & 0.023 & 0.739 & 0.570-0.959 \\ \text { Gender } & -0.621 & 0.506 & 0.537 & 0.086-3.353 \\ \text { Employment } & -2.099 & 0.064 & 0.123 & 0.013-1.123 \\ \begin{array}{l}\text { Diploma education } \\ \text { or higher }\end{array} & 2.224 & 0.006 & 9.243 & 1.872-45.632 \\ \text { Married } & -2.871 & 0.036 & 0.057 & 0.004-0.825 \\ \text { Income } & 0.910 & 0.259 & 2.483 & 0.512-12.056\end{array}$

$O R=$ odds ratio; $C I=$ confidence interval; $B M I=$ body mass index .

"All variables were entered into the model. ${ }^{\dagger}$ Knowledge was self-assessed by participants using the modified version of the Heart Disease Facts Questionnaire. ${ }^{22,23}{ }^{7}$ Continuous variable.

on the HDFQ scale by the participants indicated an inadequate level of CHD risk factor knowledge among adult Omanis. Studies from other parts of the world have similarly reported low levels of knowledge and awareness of CHD risk factors. ${ }^{7,25}$ A study conducted in Kuwait to assess public knowledge of cardiovascular disease (CVD) risk factors reported similar findings, while another conducted in Jordan reported higher levels of knowledge among their cohort. ${ }^{15,16}$

Smoking, high blood pressure and high cholesterol have been rated as factors posing the greatest risk for CHD. ${ }^{8}$ Pereira et al. reported that the prevalence, awareness, treatment and control of these risk factors in developing countries are coming closer to those in developed countries. ${ }^{26}$ The aggressive nature and consequences of these risk factors have prompted healthcare providers to give them more emphasis whilst advising patients. ${ }^{27}$ In the current study, the majority of the participants were familiar with common CHD risk factors, such as smoking, high blood pressure and high cholesterol levels. Awad et al. also reported sufficient knowledge levels among their Kuwaiti cohort regarding the risks associated with smoking, obesity, an unhealthy diet and physical inactivity; these similarities could be attributed to the frequent and comprehensive dissemination of information on the ill-effects of these risk factors by various media sources globally. ${ }^{16,28}$ However, hypercholesterolaemia, hypertension, diabetes mellitus, stress and a family history of CVD were less frequently identified as CHD risk factors among the Kuwaiti cohort. ${ }^{16}$ This may be due to inter-country variations in information provided by the mass media.
Health education and guidance are necessary to allow the general population to gain adequate knowledge from reliable sources. ${ }^{29}$

Among the cohort in the current study, the level of knowledge regarding age as a risk factor for CHD was close to the cut-off point designating adequate knowledge, reflecting a limited understanding of age as a non-modifiable risk factor for CHD. Furthermore, while the majority of the participants knew that being overweight increased the risk of CHD, fewer realised that carrying higher levels of abdominal fat imposes the greatest risk. Ford et al. noted an increasing prevalence of abdominal obesity in the USA. ${ }^{30}$ This may indicate the existence of intra-personal inhibitory factors preventing individuals from instituting measures to address this CHD risk factor. In the current study, levels of knowledge regarding HDL and LDL were low. These scores were consistent with those reported among a sample in India. ${ }^{31}$ Additionally, the participants' knowledge of stress, diabetes and a family history of CHD as risk factors was inadequate in the present study. Type 2 diabetes mellitus was found to be an independent risk factor for CVD among individuals of Middle Eastern descent living in Sweden..$^{20}$ Fernandez et al. noted that the only $46 \%$ of their Australian cohort recognised diabetes to be a risk factor for heart disease. ${ }^{32}$ Lack of awareness about family history as a CHD risk factor has also been documented in the literature. ${ }^{33}$ As a result, the risk factors which were less known to the current study's cohort may be fuelling the prevalence of CHD in Oman; this indicates an urgent need for these factors to be addressed in health education and public awareness campaigns.

In the present study, a BMI of $\geq 25 \mathrm{~kg} / \mathrm{m}^{2}$ was significantly associated with lower CHD knowledge levels. This finding is similar to that reported in a study of overweight and obese individuals in Romania which showed that participants were usually not aware of their sub-optimal health. ${ }^{34}$ Like many Arab countries, Oman has witnessed an alarming rise in its obesity rate in the last three decades, largely due to increased industrialisation, urbanisation, Westernisation, adoption of a sedentary lifestyle and improved socioeconomic status. ${ }^{35}$ Unfortunately, many obese individuals do not understand the necessity of making lifestyle changes due to a lack of knowledge about the cardiovascular implications of obesity. ${ }^{36}$ This supports the need for educational interventions to increase awareness of CHD-associated risk factors and required lifestyle changes related to eating habits and physical activity. ${ }^{37}$ Critically, a sizable number of participants in the present study believed that only physical activity performed at a gym or in an exercise class could prevent CHD. Female participants in a similar 
study from India were aware that engaging in physical activity and losing weight were important lifestyle changes required for preventing $\mathrm{CHD}^{38}$ A study from the USA found that college-level students who exercised regularly rated their CHD risk as lower than those who did not; ${ }^{32}$ this may indicate that knowledge of $\mathrm{CHD}$ risk factors can influence behaviour.

Education level was also found to have a significant association with CHD knowledge in the current study. This finding is consistent with results reported by Wagner et al. and highlights the need for multilateral interventions in order to enhance CHD awareness. ${ }^{22}$ Many of these interventions could be based in the health sector; however, others are needed at the societal level in order to increase the level of general education among the community. ${ }^{39}$ In the current study, married participants also had significantly less knowledge about CHD compared to their single counterparts. Similar results were found in a study conducted in Egypt. ${ }^{40}$ Specific marital-related factors, such as family obligations, have been found to result in a lack of time to engage in preventative actions and may therefore contribute to a lack of knowledge about CHD. ${ }^{7}$ In contrast, no significant association between CHD knowledge and gender was noted among the present cohort. This result was inconsistent with previous research by Jensen et al. which indicated that women were more aware of CHD risk factors than their male counterparts. ${ }^{41}$ Sampling bias and the larger proportion of male participants in the current study could explain this inconsistency.

The results of this study should be considered by health policy-makers when designing and implementing interventions to enhance awareness and prevention of CHD in Oman, including mass media and other community awareness campaigns. These findings could also be used to identify individuals who are likely to possess lower knowledge levels so that they can be targeted with tailored education strategies. However, further studies using larger samples and a longitudinal design are needed to validate the findings of this study. The knowledge gaps identified in this study need to be explored in greater depth by healthcare service providers and researchers to determine psycho-cognitive factors affecting lifestyle behaviours. Culturally and ethnically diverse groups and rural communities have been a common focus for studies identifying CHD risk factors. ${ }^{42,43}$ While ethnicity was beyond the scope of the current study, this factor may potentially be explored in later studies which include both the local and expatriate populations of Oman.

The current study had a number of limitations which may have impacted its findings. The cross- sectional nature of the study hindered the ability to draw inferences or generalise the findings to the larger Omani population. The use of a small convenience sample with a larger proportion of male participants, the self-selection of the group and the use of self-reported data may also have introduced inherent biases. Furthermore, the participants for the current study were attending a health awareness fair, indicating some degree of interest in health-related topics. It should also be noted that the original HDFQ questionnaire was created for diabetic patients with high health awareness, rather than to assess the general public on knowledge of CHD risk factors. As a result, the findings of this study may over- or underestimate knowledge of CHD risk factors in Oman.

\section{Conclusion}

Low levels of knowledge regarding CHD risk factors were reported among the studied group of Omani adults. While knowledge of certain CHD risk factors was adequate, fewer participants were aware of other risk factors, such as diabetes, stress, a family history of CHD, abdominal obesity, HDL and LDL. Marital status, BMI and education levels were significantly associated with knowledge levels. Health policymakers should therefore consider these findings when preparing education programmes to enhance awareness of risk factors and prevention of CHD in Oman. Further studies are needed to determine the causative factors behind the identified knowledge gaps. In addition, studies using larger sample sizes and a longitudinal design are necessary to substantiate the results of this pilot study.

\section{ACKNOWLEDGMENTS}

The authors wish to thank the study subjects for their cooperation. In addition, the authors are grateful for the support of the students and faculty who participated in the health awareness fair.

\section{CONFLICT OF INTEREST}

The authors declare no conflicts of interest.

\section{References}

1. World Health Organization. Cardiovascular diseases (CVDs). From: www.who.int/mediacentre/factsheets/fs317/en/ Accessed: Nov 2015.

2. World Health Organization. The top 10 causes of death: The 10 leading causes of death by country income group (2012). From: www.who.int/mediacentre/factsheets/fs310/en/index1.html Accessed: Nov 2015. 
3. Yusuf S, Hawken S, Ounpuu S, Dans T, Avezum A, Lanas F, et al. Effect of potentially modifiable risk factors associated with myocardial infarction in 52 countries (the INTERHEART study): Case-control study. Lancet 2004; 364:937-52. doi: 10.1016 /S0140-6736(04)17018-9.

4. World Health Organization. Global status report on noncommunicable diseases: 2010. From: apps.who.int/iris/ bitstream/10665/44579/1/9789240686458_eng.pdf Accessed: Nov 2015

5. PerkJ,DeBacker G, GohlkeH, Graham I, Reiner Z, Verschuren M, et al. [European Guidelines on Cardiovascular Disease Prevention in Clinical Practice (version 2012): The Fifth Joint Task Force of the European Society of Cardiology and other societies on cardiovascular disease prevention in clinical practice (constituted by representatives of nine societies and by invited experts)]. Eur Heart J 2012; 33:1635-701. doi: 10.1093/ eurheartj/ehs092.

6. Claassen L, Henneman L, van der Weijden T, Marteau TM, Timmermans DR. Being at risk for cardiovascular disease: Perceptions and preventive behavior in people with and without a known genetic predisposition. Psychol Health Med 2012; 17:511-21. doi: 10.1080/13548506.2011.644246.

7. Haidinger T, Zweimüller M, Stütz L, Demir D, Kaider A Strametz-Juranek J. Effect of gender on awareness of cardiovascular risk factors, preventive action taken, and barriers to cardiovascular health in a group of Austrian subjects. Gend Med 2012; 9:94-102. doi: 10.1016/j.genm.2012.02.001.

8. Mosca L, Hammond G, Mochari-Greenberger H, Towfighi A, Albert MA, et al. Fifteen-year trends in awareness of heart disease in women: Results of a 2012 American Heart Association national survey. Circulation 2013; 127:1254-63. doi: 10.1161/CIR.0b013e318287cf2f.

9. Wagner J, Lacey K, Abbott G, de Groot M, Chyun D. Knowledge of heart disease risk in a multicultural community sample of people with diabetes. Ann Behav Med 2006; 31:224-30. doi: 10.1207/s15324796abm3103_3.

10. Juwita S, Norwati D, Harmy MY, Alina TI, Siti Hawa A. Barriers to cardiovascular screening among Malay women in East Coast Malaysia. Int J Collab Res Intern Med Public Health 2013; 5:67-78.

11. National Centre for Statistics and Information, Sultanate of Oman. Data analysis. From: www.data.gov.om/en/Data Analysis/ Accessed: Nov 2015

12. Oman Ministry of Health. Health facts report 2012. From: www. moh.gov.om/documents/274609/274943/Health_Fact 2012 pdf/0b5a636f-e2e8-4400-9ef9-e1ab0d39df82 Accessed: Nov 2015.

13. Al Riyami A, Elaty MA, Morsi M, Al Kharusi H, Al Shukaily W, Jaju S. Oman World Health Survey: Part 1 - Methodology, sociodemographic profile and epidemiology of noncommunicable diseases in Oman. Oman Med J 2012; 27:425-43.

14. World Health Organization. Eastern Mediterranean Region: Framework for health information systems and core indicators for monitoring health situation and health system performance - 2015. From: applications.emro.who.int/dsaf/ EMROPUB_2015_EN_1904.pdf?ua=1 Accessed: Nov 2015.

15. Mukattash TL, Shara M, Jarab AS, Al-Azzam SI, Almaaytah A Al Hamarneh YN. Public knowledge and awareness of cardiovascular disease and its risk factors: A cross-sectional study of 1000 Jordanians. Int J Pharm Pract 2012; 20:367-76. doi: 10.1111/j.2042-7174.2012.00208.x.

16. Awad A, Al-Nafisi H. Public knowledge of cardiovascular disease and its risk factors in Kuwait: A cross-sectional survey. BMC Public Health 2014; 14:1131. doi: 10.1186/1471-2458-14-1131.

17. Shara NM. Cardiovascular disease in Middle Eastern women. Nutr Metab Cardiovasc Dis 2010; 20:412-18. doi: 10.1016/j. numecd.2010.01.013.

18. Barakat H, Barakat H, Baaj MK. CVD and obesity in transitional Syria: A perspective from the Middle East. Vasc Health Risk Manag 2012; 8:145-50. doi: 10.2147/VHRM.S28691.
19. Khosravi-Boroujeni H, Sarrafzadegan N, Mohammadifard N, Sajjadi F, Maghroun M, Asgari S, et al. White rice consumption and CVD risk factors among Iranian population. J Health Popul Nutr 2013; 31:252-61. doi: 10.3329/jhpn.v31i2.16390.

20. Bennet L, Agardh CD, Lindblad U. Cardiovascular disease in relation to diabetes status in immigrants from the Middle East compared to native Swedes: A cross-sectional study. BMC Public Health 2013; 13:1133. doi: 10.1186/1471-2458-13-1133.

21. Cohen J. A power primer. Psychol Bull 1992; 112:155-9. doi: 10.1037/0033-2909.112.1.155.

22. Wagner J, Lacey K, Chyun D, Abbott G. Development of a questionnaire to measure heart disease risk knowledge in people with diabetes: The Heart Disease Fact Questionnaire. Patient Educ Couns 2005; 58:82-7. doi: 10.1016/j.pec.2004.07.004.

23. Dalusung-Angosta A. CHD knowledge and risk factors among Filipino-Americans connected to primary care services. J Am Assoc Nurse Pract 2013; 25:503-12. doi: 10.1002/23276924.12039.

24. World Health Organization. BMI classification. From: apps.who. int/bmi/index.jsp?introPage=intro_3.html Accessed: Nov 2015.

25. Reiner Z, Sonicki Z, Tedeschi-Reiner E. Public perceptions of cardiovascular risk factors in Croatia: The PERCRO survey. Prev Med 2010; 51:494-6. doi: 10.1016/j.ypmed.2010.09.015.

26. Pereira M, Lunet N, Azevedo A, Barros H. Differences in prevalence, awareness, treatment and control of hypertension between developing and developed countries. J Hypertens 2009; 27:963-75. doi: 10.1097/HJH.0b013e3283282f65.

27. Abdullah A, Husten C. Promotion of smoking cessation in developing countries: A framework for urgent public health interventions. Thorax 2004; 59:623-30. doi: 10.1136/ thx.2003.018820.

28. Mosca L, Ferris A, Fabunmi R, Robertson RM; American Heart Association. Tracking women's awareness of heart disease: An American Heart Association national study. Circulation 2004; 109:573-9. doi: 10.1161/01.CIR.0000115222.69428.C9.

29. van Bekkum JE, Hilton S. Primary care nurses' experiences of how the mass media influence frontline healthcare in the UK. BMC Fam Pract 2013; 14:178. doi: 10.1186/1471-2296-14-178.

30. Ford ES, Li C, Zhao G, Tsai J. Trends in obesity and abdominal obesity among adults in the United States from 1999-2008. Int J Obes (Lond) 2011; 35:736-43. doi: 10.1038/ijo.2010.186.

31. Saeed O, Gupta V, Dhawan N, Streja L, Shin IS, Ku M, et al. Knowledge of modifiable risk factors of coronary atherosclerotic heart disease (CASHD) among a sample in India. BMC Int Health Hum Rights 2009; 9:2. doi: 10.1186/1472-698X-9-2.

32. Fernandez RS, Salamonson Y, Griffiths R, Juergens C, Davidson P. Awareness of risk factors for coronary heart disease following interventional cardiology procedures: A key concern for nursing practice. Int J Nurs Pract 2008; 14:435-42. doi: 10.1111/j.1440-172X.2008.00717.x.

33. Karthik S, Tahir N, Thakur B, Nair U. Risk factor awareness and secondary prevention of coronary artery disease: Are we doing enough? Interact Cardiovasc Thorac Surg 2006; 5:268-71. doi: 10.1510/icvts.2005.120956.

34. Rada C. Body mass index: Knowledge, practice and health evaluation. Int J Collab Res Intern Med Public Health 2012; 4:1276-84.

35. Badran M, Laher I. Obesity in Arabic-speaking countries. J Obes 2011; 2011:686430. doi: 10.1155/2011/686430.

36. Andersson P, Sjöberg RL, Ohrvik J, Leppert J. Knowledge about cardiovascular risk factors among obese individuals. Eur J Cardiovasc Nurs 2006; 5:275-9. doi: 10.1016/j.ejcnu rse.2006.02.005.

37. Mooney LA, Franks AM. Evaluation of community health screening participants' knowledge of cardiovascular risk factors. J Am Pharm Assoc (2003) 2009; 49:529-37. doi: 10.1331/JAPhA.2009.08120. 
38. Green JS, Grant M, Hill KL, Brizzolara J, Belmont B. Heart disease risk perception in college men and women. J Am Coll Health 2003; 51:207-11. doi: 10.1080/07448480309596352.

39. Kang Y, Yang IS, Kim N. Correlates of health behaviors in patients with coronary artery disease. Asian Nurs Res (Korean Soc Nurs Sci) 2010; 4:45-55. doi: 10.1016/S19761317(10)60005-9.

40. Seef S, Jeppsson A, Stafström M. What is killing? People's knowledge about coronary heart disease, attitude towards prevention and main risk reduction barriers in Ismailia, Egypt (descriptive cross-sectional study). Pan Afr Med J 2013; 15:137. doi: 10.11604/pamj.2013.15.137.1628.
41. Jensen LA, Moser DK. Gender differences in knowledge, attitudes, and beliefs about heart disease. Nurs Clin North Am 2008; 43:77-104. doi: 10.1016/j.cnur.2007.10.005

42. Artac M, Dalton AR, Majeed A, Car J, Millett C. Effectiveness of a national cardiovascular disease risk assessment program (NHS Health Check): Results after one year. Prev Med 2013; 57:129-34. doi: 10.1016/j.ypmed.2013.05.002.

43. Kandula NR, Patel Y, Dave S, Seguil P, Kumar S, Baker DW, et al The South Asian Heart Lifestyle Intervention (SAHELI) study to improve cardiovascular risk factors in a community setting: Design and methods. Contemp Clin Trials 2013; 36:479-87. doi: 10.1016/j.cct.2013.09.007. 